\title{
Eleştirel Uluslararası Hukuk Bağlamında Çin'in Arktik Politikalarının Analizi
}

Analysis of China's Arctic Policies in the Context of Critical International Law

Burcu GÜÇLÜ AKPINAR ${ }^{1}$

Geliş tarihi: 16.06.2019, Kabul tarihi: 25.07.2019, Basım tarihi: 25.10.2019

\section{Öz}

Bu çalışma eleştirel uluslararası hukuk bağlamında Çin'in Arktik bölgeye yönelik politikalarını analiz etmeyi amaçlamaktadır. Çin öncelikle Arktik bölge ülkelerinin egemen haklarına sayg1 duyduğunu iddia etmekte ve bu nedenle de Birleşmiş Milletler Deniz Hukuku Sözleşmesi (BMDHS) altında kendisine saygı duyulmasını talep etmektedir. Çin geleneksel uluslararası hukuk kurallarının bölge için yetersiz kaldığını ve bu durumun Arktik'te yönetimsellik açısından ciddi eksiklikler doğurduğunu düşünmektedir. Bu bağlamda Arktik'te var olma prensibini küresel politikalarla ilişkilendiren Çin'in aynı zamanda, bölge ülkeleriyle yaptığ ikili anlaşmalar vasıtasıyla mevcut hukuki yapıyı dolaylı olarak etkilediği anlaşılmaktadır. Sonuç olarak, Arktik bölgeyle ilgili olarak Çin'in savunmuş olduğu bu yeni hukuki bağlamın yakın gelecekte mevcut uluslararası hukuk mekanizmalarında reform yapılmasina neden olacağı düşünülmektedir.

Anahtar Kelimeler: Elesstirel Uluslararası Hukuk, Arktik, Cin, BMDHS, Arktik Konseyi

JEL Kodlar1: K33, F53, F50, F55

\begin{abstract}
This study aims to analyze China's policies towards the Arctic region in the context of critical international law. China primarily claims to respect the sovereign rights of the countries of Arctic region and therefore it demands to be respected own rights under the United Nations Convention on the Law of the Sea (UNCLOS). China considers that the traditional rules of international law are inadequate for the region and this situation also causes serious deficiencies in terms of governmentality in the Arctic. In this context, it is understood that China, which associates the principle of it's existence in the Arctic with global policies, also indirectly affects the existing legal structure by making bilateral agreements with the countries of the region. As a result, it is thought that this new legal context that China has advocated for the Arctic region will lead to reform of existing international legal mechanisms in the near future.
\end{abstract}

Key Words: Critical International Law, Arctic, China, UNCLOS, Arctic Council

JEL Codes: K33, F53, F50, F55

\footnotetext{
${ }^{1}$ Uluslararası İlişkiler, Dr., i.gucluburcu@gmail.com

https://orcid.org/0000-0001-5386-7714
} 


\section{Giriş}

Soğuk Savaş'in sona ermesi ve ardından sistemsel olarak bir değişim dalgasının ortaya çıkması uluslararası ilişkilerde geleneksel yaklaşımların ciddi eleştirilere tabi tutulmasını da beraberinde getirmiştir. Çünkü uluslararası sistemde tüm dünyay1 yakından ilgilendiren yeni sorun alanları ortaya çıkmıstır. Küresel çapta olmayan fakat küresel etki yaratan yerel savaşlar, kitlesel göçler, ekonomik krizler, bilimsel ve teknolojik atılımların insanlık üzerinde yarattı̆̆ sosyolojik ve psikolojik sorunlar, küresel ısınma, yönetişim, sağlık, çevre, gıda gibi diğer sorun alanları da dünya siyaseti içerisinde önem kazanmaya başlamıştır. Bu yeni sorun alanlarına geleneksel bakış açısıyla çözüm aranması ise sorunları daha karmaşı bir hale getirmiştir. Böylece, uluslararası ilişkilerin geleneksel teori ve yöntemlerinin bahsi geçen yeni sorun alanlarının üstesinden gelmede yeterli olamadıkları anlaşılmıştır. Çağdaş dünyada meydana gelen bu gelişmeler hem uluslararası ilişkiler hem de uluslararası hukuk alanında yeni teoriler çerçevesinde farklı bakış açlarının ortaya çıkmasına neden olmuştur (Gardiner, 2003: 46).

Yeni sorun alanları Arktik bölgesi üzerinde de etkiler yaratmış ve bölge uluslararası ilişkiler ve uluslararası hukuk gündeminde daha fazla yer almaya başlamıştır. Sahip olduğu eşsiz doğası ve zengin enerji kaynakları bölgeye kıyısı olsun ya da olmasın bütün devletlerin dikkatini çekmiştir. Özellikle küresel ısınma, bölgede hareket etme kabiliyetinde artış sağlamış, bölgedeki aktör ve faaliyet çeşitliliği de burada yeni düzenlemeler yapılmasını gerekli kılmıştır.

Arktik bölge küresel anlamda insanlığın sahip olduğu ortak varlıklar (global commons) kategorisi içerisinde belirtilmiştir (Schrijver, 2016: 1253). Dünyanın kara, deniz, hava ya da uzay alanlarının ulusal/uluslararası yasal yetki alanlarına göre ayrılması özellikle iklim ve ona bağlı yaşanan değişimler söz konusu olduğunda anlamını yitirmiş ve bu alanların yasal sınırlarını küresel ölçeğe taşımıştır (Schrijver, 2016: 1262-1263). Ayrıca dünyanın ekolojik döngüsünde sahip olduğu değerli konumuyla Arktik, kıyı ülkelerinin egemenlik alanlarına terk edilecek kadar sıradan bir bölge olmadığını göstermiştir. $\mathrm{Bu}$ nedenle Arktik'te uluslararası sorumluluk isteyen bir yönetişim anlayışının tesis edilmesine olan ihtiyaç artmışıtır. Küresel ölçekte Arktik'in yönetişimini sağlayacak uluslararası yasal statüsü olan bir örgüt bulunmamaktadır. Kıyı ülkeleri tarafindan oluşturulan Arktik Konseyi ise fonksiyonel anlamda ve küresel ölçekte arzu edilen yönetişimi sağlamaktan uzaktır. Arktik Konseyi hukuki bir bağlayıcilığı olmayan, resmi karar alabilecek bir otoritesi bulunmayan bir yap1 olarak kalmıştır (Young, 2012: 173-174). Ayrıca bu yap1 bölgenin karşı karşıya kaldığ1 sorunlarla baş edebilme konusunda yetersiz bulunmuştur. Gözlemci üye ülkelerin karar alma mekanizmalarında etkin rol alamaması ve sadece daimi üyelerin egemenliklerini korumak ve güçlendirmek için bu yapının kullanılıyor oluşu 
diğer ülkeler tarafından eleştirilmiştir. Bununla birlikte söz konusu yapının küreselleşen meseleler karşısında fazla dayanamayacağına vurgu yapılarak Arktik Konsey'in ihtiyaç duyulan reformları yerine getirmesi tavsiye edilmiştir (Rainwater, 2015: 148-151). Arktik Konsey'in daimi üyelerinin dünya siyasetinde önemli görülen aktörleri kapsıyor oluşu onu siyasi bağlamda işlev gören bölgesel bir yapı olmaktan kurtaramamıştır.

Arktik Konsey'in uluslararası bir anlaşmayla kurulmuş, yasal statüsü bulunan bir örgüt olmadığı ifade edilmektedir. (Takei, 2015: 353-355) Bu duruma rağmen Arktik Konsey'in bölgeyle ilgili olarak nihai karar alma yetkisinin sadece kendi asli üyelerine ait olduğunu belirtmesi hususu ise (Rainwater, 2015: 143) Arktik'e kiyısı olmayan ülkeler tarafindan olumlu karşılanmamaktadır. Çünkü Arktik Konsey kendisi hukuki bir bağlayıcılık temelinde kurulmayıp sadece BMDHS'ni kendisine referans alan bir yapıdır. Bu yapı sadece bölge ülkelerinin ortak çıarlarını korumaya hizmet eden bir oluşumdur.

Diğer taraftan Bennett'e (2015: 653) göre ise Arktik ülkeleri, Arktik bölgede toprağ1 bulunmayan diğer ülkelerin bu bölge üzerinde küresel söylemlerde bulunmalarına iyimser yaklaşmamakta ve bunu egemenliklerine karşı bir güvenlik sorunu olarak görmektedirler. Bu yüzden Konsey’in daimi üyeleri bölgedeki egemenlik alanlarını güçlendirmek için yaptıkları işbirliğinde yine bu konsey çerçevesinde hareket etmektedirler.

Arktik bölge üzerinde sürüp giden uyuşmazlıkların yasal bir zeminde çözüme ulaştırılma çabalarında ise uluslararası hukuk mevzuatına başvurulduğu gözlenmiştir. Nitekim Arktik'te mevcut sorunlara genel olarak BMDHS ile ikili anlaşmalar çerçevesinde çözüm bulma arayışı olmuştur. Fakat geleneksel uluslararası hukukun da bu sorunlara tam anlamıla çözüm sunamadığ1 anlaşılmıştır. Schrijver (2016: 1256) çalışmasında okyanuslar anayasası olarak tanımlanan BMDHS'nin açı denizlerdeki faaliyetleri tam olarak yönetemediğini ve bu nedenle de ek anlaşmaların yapılması suretiyle hukukta yer alan bu boşlukların doldurulmaya çalsşıldığını belirtmiştir. Bu kapsamda Arktik bölgede arama kurtarma, olası petrol kirliliğine hazırlık ve müdahale, bilimsel işbirliğinin geliştirilmesi vb. alanlarda ek anlaşmaların da yapıldığ1 gözlenmiştir (https://arctic-council.org, 2019).

Mevcut hukuk kurallarının yeterli gelemediği durumlarda yenilerinin ortaya çıkması kaçınılmaz bir hal almaktadır. Yeni sorun alanlarıyla beraber değişen bu dünyada, Arktik'te düzen sağlayıcı unsurların da değiştiği gözlenmektedir. Uluslararası hukuk bu bağlamda Arktik'te değişen ve gelişen bir yaşam döngüsü içine girmiştir. Çünkü Arktik sadece bu bölgede toprağ bulunan ülkelerin meselesi olmaktan çıkmıstır. Arktik'te problemlerin küresellik arz ettiği açıktır. Hatta kimi ülkeler buradaki sorunların kendi ülkelerindeki yaşam ve gönenç sorunlarıyla bütünleşik olduğunu iddia etmektedirler (Nanda, 2019). Bu bağlamda bölgede kıyısı bulunmayan 
ülkelerin Arktik'te özellikle bilimsel, siyasal ve ekonomik faaliyetlerde yer alma çabaları dikkat çekmektedir. Çin de bu ülkelerden biridir. Bu makalede Çin'in Arktik bölgedeki uluslararası hukuk ve yönetim anlayışına yönelik politikası, eleştirel uluslararası hukuk çerçevesinden analiz edilmeye çalışılacaktır.

\section{Kuramsal Çerçeve}

Schmitt (2012: 146) “devletlerarası ilişkileri düzenleyen uluslararası hukukun, siyasal birliğin ve yeryüzündeki mekânsal düzenin zamana bağl1, tarihsel tezahür biçimleriyle sınırlı olduğunu" dile getirmiştir. Bu bağlamda uluslararası ilişkileri düzenleyen uluslararası hukuk kurallarının da değişim geçirmesinin tarihsel nedenlerden kaynaklandığını belirtmek yanlış olmaz.

Kennedy (1996: 390-401) ise 19.yy klasik uluslararas1 hukuk sisteminin 17. yy'a dayanan felsefi prensiplerden ve diplomasi tarihinden etkilenerek kurulduğunu belirtmiştir. 20.yy'da ise karasuların artık 3 deniz mili olarak kabul edilmediğine dair örneği vererek hukuk sisteminde belirli alanlarda zamansal etkiyle revizyon yaşandığına dikkat çekmiştir.

Günümüzdeyse bu çalışmanın giriş kısmında belirtilen sorunlarla ortaya çıkan ilişki ağları uluslararası ilişkiler ve uluslararası hukuk gündemini meşgul ederek bu alanların yeniden yorumlanmalarına sebep olmuştur. Geleneksel uluslararası hukuk anlayışına bir eleştiri olarak ortaya çıkan fakat bu geleneksel yapıyı tamamen ortadan kaldırmayan eleştirel hukuk anlayışında kararların hukuk dışı birçok alandan özellikle de siyasetten ayrı tutulamayacağ1 vurgulanmıştır (Pazarc1, 2010: 8). Bilhassa ulus-devlete ait iç hukuk kurallarının öngördüğü birtakım kısıtlamalar, hiyerarşik düzlemde uluslararası hukukun geride kalmasına ya da iç hukukla eşit düzlemde yer almasina sebep olmuştur (Pazarc1, 2010: 21-23).

Eleştirel hukuk çerçevesinden düşünüldüğünde, iç hukukun uluslararası hukuktan üstün ya da ona eşit olarak kabul edildiği bir ülkede uluslararası hukuku ilgilendiren bir durum karşısında egemen gücün alacağı karar, "ulusal çıkarların” mi yoksa "adaletin” mi etkisi altında kalacaktır? İç hukuk uluslararası hukuktan üstün görülüyor ise egemen olan siyasal bağlamından ne derece uzak kalacaktır? Hukuk ve adalet ilişkisinde hiyerarşik sıralamayı belirleyici unsur ne olacaktır? Bu sorular mevcut uluslararası hukuk düzenine karşı bir eleştiri oluşturmanın dışında yeni anlayış ve bakış açılarıyla birlikte değişimi de gündeme getirmektedir.

Örneğin Antik Yunan döneminin ünlü tragedya yazarlarından biri olan Sophokles, Antigone adlı eserinde (2018: 1-53) egemenliğin ve adaletin nasıl şekillendiğini anlamamıza yardımcı olmaktadır. Bu eserde başkarakter olan Antigon, hak ve adaletin vücut bulmuş hali Dike'nin (Antik Yunan'da adalet tanrisı) insanlara sunduğu yasayla Thebai Şehrinin Kralı Kreon'un egemen 
yasası arasında ikilemde kalmışıtır. Kreon'un, Dike’nin yasasını askıya alarak kendi yasasını kurmasına Antigon karşı çıkmıştır.

Agamben (1998: 15) de egemenliğin paradoksundan bahsederken egemen olanın, kendisini hukuksal alanın dışında konumlandırarak mevcut hukuki durumu askıya alma rolüne ve bu rolün hukukun sinırlarını belirlemedeki etkisine dikkat çekmektedir. Mevcut hukukun da istisna/hukuk dışı alan belirlemesi nedeniyle sorun alanı oluşturduğunu söylemek mümkün hale gelmektedir. Bu durumda egemen gücün temel olan yasayı kendi çıkar alanını korumak uğruna yok sayarak/erteleyerek (istisna yaratarak) hukuk içinde hukuksuz bir durum meydana getirdiği, egemene karşı gelen Antigon'un ise temel yasayı (adaleti) kendi yasası haline getirerek yeni bir hukuk ilişkisi yarattığı ortaya çıkmaktadır. Antigon'un bu bağlamda kendi egemenliğini kurduğu da söylenebilir.

Adaletsiz olarak tanımlanan iktidarların koymuş olduğu yasalar en nihayetinde dışarıdakileri kapsamadığ için mutlak olmayacak ve bu durum dışarıdakilerin direnişiyle birlikte yeni iktidar ve hukuk modeli ihtiyacını ortaya çlkaracaktır (Foucault, 2011: 294-295). Böylece belirli bir kesimin kendi bilgi/iktidar söylemi üzerinden tanımladığı tek taraflı hukuk anlayışına karşı diğer aktörlerin adalet taleplerini de kapsayacak yeni bir uluslararası düzen ihtiyacı oluşmaktadır.

$\mathrm{Bu}$ durum uluslararası ilişkiler ve uluslararası hukuk çerçevesinden düşünüldügünde, mevcut sistem üzerinde etkili olabilecek bir takım yeni hakların hukukundan bahsetmeyi de olanaklı kılmaktadır. Mevcut egemen yapının tarihsel bağlam çerçevesinde sunmuş olduğu geleneksel hukuk kuralları ile hukuk dışında kalanların (ötekileştirilenlerin) adalet taleplerinin karşılanması sorunu yeni paradigmaların gerekliliğini ortaya çıkartmaktadır.

\section{Geleneksel Uluslararası Hukukun Eleştirisi}

Geleneksel uluslararası hukuk tarih boyunca birçok açıdan eleştiriyle karşılaşmıştır. Uluslararası hukukta eleştirel çalışmalar ilk etapta yeni bir hukuk rejimi ya da yasalar oluşturmanın peşinde olmamış ancak var olan hukuk sistemini sorunsal hale getirerek üzerinde çalışmayı esas almışır (Koskenniemi, 2016: 729-734). Örneğin, neden yasal kurumların ya da düzenlemelerin "sistemli olarak belirli güçlerin çıkarlarını koruduğu" sorgulanmış, bu düzenin ardında yatan mantığın, diğer bir deyişle yapının ortaya çıarılması üzerinde durulmuştur (Koskenniemi, 2016: 734). İkinci Dünya Savaşı sonrasında, üçüncü dünya ülkelerinin Batılı devletlerin lehine olan bir takım kuralları tenkit ederek uluslararası hukuk kurallarında reform yapılmasını dile getirdikleri bilinmektedir (Meray, 1977: 39). Batı'nın ortaya çıkartmış olduğu mevcut uluslararası düzenin bir parçası olan ortak değerlerin batılı olmayan devletler tarafindan bir dayatma olarak algilanması, bu yapının hukuksallığını sorunlu hale getirmiş̧ir (Koskenniemi, 2005: 474- 
484). Dünya siyasetinde hâkim olan yapının, sahip olduğu siyasi vaziyeti uluslararasılaştırarak bu durumu tüm uluslararası alana yayması/dayatması hukukun objektifliğine halel getirmektedir.

Örneğin; "9/11 olaylarının ardından terörizmle ve nükleer silahların yayılımıyla ilgili olarak BM Güvenlik Konseyi nezdinde alınan 1373 ve 1540 nolu kararlarla ABD, en üst seviyedeki güvenlik endişeleriyle ilgili önceliklerini tüm üye ülkelerin uymak zorunda kaldığ1 genel yasal yükümlülüklere dönüştürmüştür”'(Kınacioğlu, 2012: 77).

Uluslararası sistemde hâkim söylemin veyahut gücün savunmayı tercih ettiği hukuk ilkelerinin evrensel prensipler olarak kabul edilmesini istediği, herhangi bir çatışma durumunda ise hukuk kurallarını sadece kendi siyasal gücünü destekleyecek şekle getirdiği anlaşılmaktadır (Koskenniemi, 2004: 199-200). Günümüz uluslararası sisteminde başat güç olan ABD'nin BM Güvenlik Konseyinde yapılan yasaların uygulanması konusunda ayrıcalıklı bir konumda bulunuyor olması(Krisch, 2005: 398-399) hukukun eşit şekilde uygulanması prensibine aykırı düşmektedir. Yukarıda verilen bu örnekle sadece sistemde baskın olan söylemin hukuki düzlemde de nasıl etkin olduğu vurgulanmış ve hukukun bir bakıma baskın gücün çıkarına hizmet eden siyasal bir araç haline dönüştügüne dikkat çekilmiştir.

\subsection{Eleştirel Uluslararası Hukukta Hukuk-Siyaset İlişkisi}

Geleneksel uluslararası hukukun sahip olduğu bir takım özelliklere karşı yapılan eleştiriler; Akman'ın (2012: 1284) ifadelerinden de anlaşılacağı üzere: "iktidar savaşı, ekonomik rekabet ve üstünlük mücadelesi, belirli bir grubun veya bireyin başka grup ve bireyler üzerinde egemenlik kurma istençleri gibi" hususlarda yoğunlaşmış ve hukukun siyasetle olan bağını ortaya çıkartmaya odaklanmıştır.

Örneğin, Koskenniemi (2004: 440-445) siyasal olan ile hukuki olan arasında asimetrik bir ilişkinin varlığından bahsederek siyasetin her daim önde olduğunu ve uluslararası ilişkilerin de uluslararası hukukla değil uluslararası siyasetle anlamlandırılabileceğine değinerek hukukun zayıflı̆̆ına dikkat çekmiştir. Bu bağlamda uluslararası hukuk kuralları sistemde baskın olan siyasi egemen(ler)in çıkarlarını önceleyerek ve onlara hizmet ederek hukukun sorunsal hale gelmesine neden olmaktadır. Diğer bir örnekte ise BMDHS'nin deniz yatağı ile ilgili olan kısmının tarihsel olarak gelişiminde hukuki olmayan ekonomik, siyasal gibi alanlara dayalı söylemlerin etkin rol oynayarak sözleşmeyi şekillendirdiği gözlenmektedir (Koskenniemi ve Letho, 1996: 552-555). Her iki örnekte olduğu gibi hukuk kurallarının şekillenmesinde siyaset ve ekonomi gibi hukuk diş1 faktörlerin önemli rol oynadığı anlaşılmaktadır. Bu bağlamda hukukun siyaset, ekonomi vb. hukuk dışı alanlardan bağımsız düşünülemeyeceği değerlendirilmektedir. 
Yukarıdaki örnekleri destekleyecek şekilde Brezilya'da neo-liberal ekonomiden yeni kalkınmacılık (new-developmentalism) modeline geçiş yapılırken hukuki anlamda da bir değişim yaşandığına dikkat çekilmiş, devletin ulusal ekonomik-siyasal tercihinin hukuki değişimleri tetiklediği ifade edilerek (Trubek, 2013: 3-15) siyasal değişimle hukuki değişim arasında bir ilişki bulunduğu ortaya çıkarılmıştır.

Peki, siyasal olanla hukuksal olanın birbiri içine geçmediği bir uluslararası hukuk düzlemi nasıl tahayyül edilecektir? Uluslararası hukuk kuralları zorunlu olarak belirli bir siyasal tercih çerçevesinde oluşturuluyorsa hukukun objektifliğinden ne derece bahsedilecektir? Adaletin tesis edilebilmesi noktasında mutlak devlet egemenliği mi yoksa uluslararası hukuk mu referans alınacaktır?

\subsection{Devlet Egemenliğine Karşı Uluslararası Hukuk}

Vestfalyan egemenlik anlayışına göre (buna Batı menşeili de denilebilir) ulus-devletler eşit egemenlerdir ve onların üstünde hiçbir güç bulunmamaktadır. Bu egemenler kanun yapıcı ve kural koyucu olarak etkin bir rol üstlenmiştir (Anghie, 2014: 126).

20. yüzylın uluslararası hukuk düzeninde egemen devletlerin koşulsuz hâkimiyet üstünlüğüne sahip olmalarının bir takım dezavantajları olmuştur. Uluslararası sistemde yer alan tüm egemenleri bağlayıcı uluslararası hukuk düzeninin oluşturulması ve bununla ilgili teorik tartışmaların geliştirilmesi konusunda zorluklar yaşanmıştır (Kennedy, 1996: 400-401). Anghie (2014) ve Kennedy'nin (1996) yorumlarından Vestfalya'dan günümüze kadar olan tarihsel süreç boyunca "devlet egemenliğinin" "uluslararası hukuka" üstün bir konumda yer aldığı fikri ortaya çıkmaktadır.

Uluslararası düzenlemelerin devletin ilişkilerini etkilediği durumlarda egemenlik hususunun ön plana çıktı̆ı anlaşılmaktadır. Örneğin, BMDHS devletlerin denizlerdeki egemenlik alanlarını kanunla belirlerken diğer devletlerin de haklarını koruma prensibi çerçevesinde kıyı ülkesine hareket kisitlamasi getirmektedir (Abbott ve Snidal, 2001: 53-54). Bu düzenlemeye uyup uymamak ise devletlerin tekeline bırakılmışıtır. Egemen güç (devlet) aynı zamanda yasayı kabul et(me)me gücünü elinde bulundurarak, yasanın kesinlik prensibini ortadan kaldırmaktadır. Yasanın kesinliği egemen gücün iradesine bağlanmıştır. Koskenniemi (2005: 17) daha da ilerisine giderek "hukuk yaratımının sübjektif siyasal bir tercih meselesi" olduğuna dikkat çekmektedir. Ayrıca devlet uluslararası hukukun bağlayıcı gücünü elinde bulundurarak, uluslararası hukukun üstünlüğü prensibini daha ilk başlarda problemli hale getirmiştir (Lauterpacht, 2011: 3-5).

Egemen ve hukuk arasındaki hiyerarşik mücadelenin iki karşıt doktrin çerçevesinde analiz edildiği de olmuştur. Hukuksal kaynaklara dayalı doktrine göre yargının kesin üstünlüğü bulunup, egemenliğin hukuktan 
bağımsız bir anlamı olmadığına dikkat çekilmiştir. Egemenlik doktrinine göre ise hukukun kaynaklarının egemenin dikkate aldığı kadarıyla -ve egemenin onaylamasına bağlı olarak- önem kazandığ1 vurgulanmıştır (Koskenniemi, 1997: 569-570). Her iki doktrinin de kendi söylemlerini bir diğeri üzerinde üstün kılma çabası uluslararası hukukun yorumlanmasında zorluklar oluşturmuştur.

Krasner (1999: 70) ise Soğuk Savaş dönemindeki uluslararası hukuk düzeninde devletin egemenliğinin tanınmasının bir kurala bağlı olmadığını dile getirerek Çin ve SSCB örneğinde olduğu gibi tanınmama durumunda varlıklarının inkâr edilemeyeceğine dikkat çekmiştir. Buradan hareketle uluslararası sistemde baskın olan anlayışın hukukuna tabi olmadan da siyasi varlığın sürdürülebileceği değerlendirilmektedir. Bir egemenin var olması için hukukun onu tanıma zorunluluğu bulunmamaktadır. Burada devlet egemenliğinin uluslararası hukuka bağlı olmaksızın siyasi varlığını koruduğu anlaşılmaktadır.

Günümüzde ise yeni egemenlik kavramından bahsetmek başka ülkelerin egemenlik hakkının da tanınması anlamına gelmektedir (Humrich, 2013: 90). Diğer bir ifadeyle egemenlik kavramı karşılıklı olarak birbirinin hakkını tanımayı gerektirmektedir. Buna dayanarak Arktik bölgede kıyısı bulunmayan ülkelerin bu bölgeyle ilgili hak taleplerinin dikkate alınması gerektiğini ve egemenliğin mütekabiliyet esasına göre anlam kazandığını söylemek mümkündür. Fakat bu duruma yönelik olarak farklı bakış açılarının yer aldığı gözlenmektedir:

Örneğin Rusya Dış İşleri Bakanı Lavrov, 7 Mayıs 2019'da on birincisi yapılan Arktik Konseyi Bakanlar toplantısında Rusya'nın Arktik'te daha kapsamlı bir işbirliğine açık olduğunu dile getirirken, uluslararası hukukun bölge ülkelerinin ulusal çıarlarının yanı sıra bölgede bulunmayan diğer konsey üyelerinin çıkarlarının sağlamasına da olanak sunduğunu ifade etmiştir (https://ruptly.tv, 2019). Lavrov'un bu konuş̧ması Arktik'te kıyıs1 bulunmayan ülkelerin deniz sözleşmesinin kendilerine sunmuş olduğu egemenlik haklarından yararlanabileceklerine dair bir onay olarak yorumlanmıştır. Diğer yandan aynı toplantıda ABD Dış Iş̧leri Bakanı Pompeo, Çin'in "Arktik bölgeyi bir rekabet alanına dönüştürerek üzerinde yasal hak talep edilebilecek bir sahaya çevirebileceğine" dikkat çekmiştir (Sengupta, 2019). Yukarıdaki her iki örnekte Rusya ve ABD'nin Arktik konusunda kendi egemenlik alanlarında farklı görüsslere sahip oldukları ve bu bağlamda uluslararası hukuku da farklı yönlerden yorumladıkları anlaşılmaktadır. Ülkeler aynı hususlarda dahi farklı yorumlamalarda bulunarak egemenliğin uluslararası hukukun önünde oynadığı rolü gözler önüne sermektedir. 


\section{BMDHS'ne Yönelik Eleştiriler}

Eleştirel uluslararası hukuk savunucuları yasaların oluşturulması, uygulanması, geçiciliği, objektif olmaması vb. gibi genel konuların dişında BMDHS gibi hukuki metinlerle ilgili de eleştiriler yapmaktadır. Bu metinlerin modernist bağlamda oluşturulduğuna vurgu yapılarak mevcut uluslararası sorunlar karşısında yetersiz kaldığı iddia edilmektedir.

Koskenniemi (2005: 490) BMDHS'nin devletlerin okyanuslar üzerindeki talepleri konusunda coğrafi alanların belirlenmesi ve sınırlandırılması ile ilgili hükümlerini belirlerken bunu kavramsal karşıtlıklar (ikili karşıtlıklar çerçevesinde inşa etme durumu) çerçevesinde yaptı̆̆ına dikkat çekerek aslında bu mekânsal-kavramsal ayrımların daha derin ayrılıkları ortaya çıkardığını düşünmektedir. Ayrıca sözleşmenin deniz yetki alanlarının sınırlarını belirlerken kullandığı ikili karşıtlık yönteminin egemen olanın hakkını korumaya hizmet ettiği değerlendirilmektedir.

Örneğin, BMDHS deniz alanları ile ilgili hükümlerde bulunurken aslında sahildar devlet ile bitişik devlet ya da kendi egemenlik alanında seyrüsefer yapan geminin bağlı bulunduğu devlet arasında kanunla ayrılıklar yaratarak birini diğerinin ötekisi haline getirmektedir. BMDHS'nin coğrafi alan üzerinde sinırlandırmaları mesafeleri dikkate alarak yapması ve bu sinırlar içerisinde "neyin yapılıp yapılamayacağına değil de kimin yetkin olup olamayacağına odaklanması" hukuk içerisinde bir boşluk yaratmaktadır (Koskenniemi, 2005: 490-491). Deniz alanını kullanmak durumunda kalan ya da kullanma amacı güden devletler nezdinde hukuktaki bu boşluk ihtilaf yaratmaktadır. Bu boşlukların sadece devletler üzerinde değil tüm küresel toplum üzerinde de etkileri bulunmaktadır. Örneğin BP şirketinin Meksika Körfezi'nde neden olduğu deniz kirliliğini ele alan Hickey (2014) derin sularda sondaj yapılması ve ekosisteminin korunmasiyla alakalı olarak deniz hukukunun bir dizi eksikliği bulunduğunu, BM'nin balık stoklarıyla ilgili anlaşmasını örnek vererek konuyla ilgili benzeri bir anlaşmanın gerekli olduğunu ifade etmiştir. Denizlerdeki kirlilik doğrudan ve dolaylı olarak insan yaşamı üzerinde tehdit oluşturmaktadır. Bu bağlamda denizlere sadece hukuki kıstaslar koyarak yapılacak bir düzenlemenin bu alanları güvenli k1lmayacağ1 değerlendirilmektedir.

Okyanuslara ekonomik ya da ekolojik amaçlarla değil, hukuki yeterlik bağlamında yaklaşan BMDHS kurallarının, devletlerin deniz alanlarının korunmasına ilişkin sorumluluklarına detaylıca değinmediği ifade edilmiştir (Koskenniemi, 2005: 488). Schrijver (2016: 1261) ise Uluslararas1 Balina Avc1lı̆̆1 Komisyonu ile Uluslararası Deniz Yatağ1 Otoritesi'ni uluslararası hukuk kurallarını açıkça ortaya koyan ve düzenleyen mevcut en iyi iki örnek olarak göstermiş fakat bunların da yasal uygulama problemleri olduğundan bahsetmiştir. 
Diğer taraftan okyanuslardaki kaynakların sinırlllı̆̆ nedeniyle doğacak herhangi bir çatışma halinde sözleşmenin çatışmaları önleyici ve onları hukuki bir zemine bağlayıcı kurallar koymada eksikleri bulunduğu ve sözleşmenin bu bakımdan yetersiz kaldığ1 vurgulanmışır (Koskenniemi, 2005: 493). Özellikle Arktik'te kıta sahanlığına bağlı olarak egemenlik alanını genişletme çabalarının ortaya çıkardığı risklerin bu bağlamda düşünülmesi gerekmektedir.

Sözleşmenin karasuları, bitişik bölge, münhasır ekonomik alan ve kıta sahanlıklarıyla alakalı eleştirilerinin yanı sıra, açık denizlerle ve deniz yatağı ile ilgili olan kısımlarına yönelik de belirli bir takım eksiklikleri barındırdığı düşünülmektedir. Örneğin açı denizlerin daha önceki dönemlerde, aynı kara parçaları gibi birer egemenlik alanı olarak idrak edildiği ve okyanuslar üzerindeki hâkimiyet taleplerinin tarih boyunca sürdüğ̈u bilinmektedir (Pahuja, 2012: 411). Modern uluslararası hukukla birlikte bu anlayışın terkedilerek yerini açık denizlerin özgürlügü prensibine bıraktı̆̆1 görülmektedir. Nitekim Meray (1977: 118) uluslararası hukuka dayanarak açık denizi özgürlük alanı olarak ifade ederek buradaki faaliyetlerden kaynaklanan hukuki bir durum söz konusu olduğunda ise yarg1 yetkisinin sadece bayrak devletine ait olduğunu belirtmiştir. Uluslararası hukuk kurallarına göre açık denizlerde uyrukları üzerinde yargılama yetkisi devletlere verilmiş̧ir. Sur (2010: 353) ise açık denizlerdeki özgürlüğün sınırsız olmadığını, belirli şartlara bağlandığını ifade etmiş, özellikle serbestlik içeren konuları "denizde seyahat edebilme, hava sahasını kullanma, balıkçılık faaliyetinde bulunma ve deniz altına kablo ve boru döșeme" olarak dört gruba ayırmış "yapay adaların inşası" ile "bilimsel araştırma" haklarını da bunlara eklemiştir.

Diğer taraftan açık denizlerde müdahale etme yetkisinin meşru müdafaa kapsamına giren bir olayda nasıl gerçekleşeceği BMDHS'nin üzerinde açıklama yapmadığı bir husus olarak karşımıza çıkmaktadır (Sur, 2010: 355). Aynı şekilde BMDHS'nin açık denizlerde takip hakkıyla ilgili olan kısmında hangi mesafelerin esas alınması gerektiği belirtilmesine rağmen bu izlemenin hangi kurallar çerçevesinde yapılacağı açıkça ifade edilememektedir (Sur, 2010: 356).

Tüm bunlara ek olarak BMDHS'nin uluslararası deniz yatağını ilgilendiren 11. Bölümünün 2. Kısmı deniz yatağı ve onun kaynaklarının tüm insanllğa ait olduğunu ifade ederek buranın yönetilmesiyle ilgili bilgiler vermektedir (https:/ /www.un.org, 2019). Fakat Koskenniemi'nin (2005: 39) de belirttiği gibi deniz yatağıyla ilgili olarak "insanlığın ortak mirası" deyiminin egemenlik (sovereignty) bağlamında m1 yoksa dokunulmazlık (immunity) bağlamında $\mathrm{m} 1$ yorumlanması gerektiği ile ilgili bir belirsizlik bulunmaktadır. Söz konusu bölgeye yönelik yorumlamalardaki farkllığın ilgili hukuk metni üzerinde de değişimler yaratacağı tahmin edilmektedir. 
BMDHS'nin bunun gibi birçok hususta eksik kalan yönlerinin bulunduğunu söylemek mümkündür. Bu çerçevede metinsel olarak hükümler sunan uluslararası hukuk prensiplerinin gerçek olaylarla ilgili problemleri tam kapasite yönetecek yeterliklere sahip olamadığ1 anlaşılmaktadır. Anlaşmada tespit edilen eksikliklerin giderilmesine ve ek anlaşmalar yapılmasına ihtiyaç duyulduğu değerlendirilmektedir.

\section{4. Çin'in Arktik Stratejisinin Uluslararası Hukuk Bağlamında Analizi}

\section{1. Çin'in Arktik'te Var Olma Dayanağı}

Rainwater'a (2013: 69) göre iklim değişikliğinin Aktik bölgede yarattığ1 etki Çin'in enerji için hammadde temin arayışı ile alternatif ticari rotalar belirleme ihtiyacını gün yüzüne çıkartmıştır. Bu söyleme göre, Çin’in Arktik'te var olma amacının -enerji temini ve ticari kaygılar çerçevesindensalt eknomiye indirgenmesi olasıdır. Fakat Çin'in Arktik'te sadece ekonomi odaklı politikalar yaptığını düşünmek gereksiz bir sınırlandırma sunacağ1 gibi yanıltıcı da olabilir. Çin, Rusya gibi 21. yüzyılın uluslararası sistemini çok kutuplu olarak görmektedir. Çin bir bakıma bu politikayı güderek uluslararası sistemdeki dengeleyici rolüyle buna bağlı olarak artan etkin pozisyonuna gönderme yapmaktadır (Mastanduno, 2001: 28-29).

Uluslararası sistemi çok kutuplu bir yapı olarak görmenin ne hegomonya karşıtlı̆̆1 ne de anarşi taraftarlı̆̆1 anlamına gelmediği belirtilmiştir (Müllerson, 2003: 232). Çok kutupluluk bu bakımdan dünya siyasetinde etkin güçlerin bir arada varlık sergileyebilecekleri bir düzene gönderme yapmaktadır. Çin de bu çok kutuplu sistemi benimseyerek tüm dünyayı ilgilendiren politikalarda alternatif bir düzen tahayyül etmektedir (Savin, 2018). Arktik bölge de Çin’in bu tahayyülü içerisinde konumlanmaktadır.

2008'de Arktik Okyanusu'na sınırı bulunan beş ülkenin bir araya gelerek yayımladıkları Ilulissat Deklerasyonu ile bir tür Arktik bölgeselciliği yaratmaya çalıştıkları anlaşılmıştır. Bu duruma Arktik bölgede toprağ1 bulunmayan ülkelerden özellikle Çin'in tepki verdiği ve bölgede farklı alternatif yapılanmalar üzerinde çabaladığ1 gözlenmiştir (http://www.europarl.europa.eu, 2019).

Çin'in askeri ve güvenlik gelişmelerinin ele alındığı 2019 yılı Amerikan Kongresi Raporuna göre, Arktik konseyine gözlemci üye olarak katıldı̆̆1 2013 yılı itibariyle Çin bu bölgeyle olan ilişkisini arttırmıştır. Çin’in Arktik bölgeye yönelik ilgisinin sadece maddi unsurlardan kaynaklanmadı̆̆1, "başlica sorumlu ülke" (responsible major country) sıfatıyla da bölge politikalarının içerisinde yer alacağ belirtilmiştir (https://media.defense.gov/2019). Çin'in kendisini bu şekilde kimliklendirmesinin Arktik bölgede etkin olan ABD, Rusya, AB gibi diğer aktörlere yönelik bir mesaj niteliği taşıdığ düşünülmektedir. 
Çin'in kendisini Arktikle ilişkili olarak kimliklendirdiği diğer bir söylemi ise "Yakın-Arktik Devleti" (near-Arctic state) olarak karşımıza çıkmaktadır. Fakat bu kimliğin, Arktik bölgede hukuki olarak varlık göstermeye olanak tanıyan uluslararası bir anlaşmanın olmaması dolayısıyla Çin'e yasal anlamda bir fayda getirmeyeceği düşünülmektedir. Yine de bu kimlik Çin'in Arktik bölgeyi uluslararası bir konuma getirme çabalarının bir ifadesi olarak değerlendirilebilir (https://worldview.stratfor.com, 2019).

Diğer yandan, Çin rüyasının bir aşaması olarak görülen Bir Kuşak Bir Yol projesinin Arktik bölgeyi de içine alan Kutup İpek Yolu (Polar Silk Road) kısmı diğer Arktik ülkeleriyle işbirliği çerçevesinde geliştirilmiştir (Lim, 2018: 9-12). Fakat bu duruma yönelik bir takım karşıt değerlendirmelerin yapıldı̆̆1 gözlenmiştir. Örneğin, Çin’in deniz ipek yolu olarak adlandırdığ1 bu güzergâhın, Rusya'nın Arktik kıyıları boyunca uzanan Kuzey Denizi Rotasıyla (Northern Sea Route) çakışması halinde bölgede yeni güvenlik sorunlarının ortaya çıkabileceği değerlendirilmiştir (Tucker, 2019). Bir diğer geçiş güzergâhıyla ilgili olarak Byer'ın ifadesinde yer aldı̆̆ı şekliyle Çin, Kanada'nın Arktik bölgesinde yer alan Kuzey Batı geçidini Kanada'nın egemenlik alanı içerisinde kabul etmekte ve buradan yaptığı geçişlerde Kanada hükümetinin onayını almaktadır (Byer'den aktaran Sevuntus, 2018: 17). Çin, hem Rusya hem de Kanada'nın kendi iç suları olarak kabul ettiği bu iki geçit üzerinde her iki devletin egemenlik haklarını tanımaktadır. Çin Arktik bölge üzerinden geçen ticaret yollarının güvenliğine önem vererek bu konuda olumsuz politikalar sergilemekten kaçınmaktadır.

Zaten China Today dergisinde (2018: 6) de Çin’in bu bölgeyle ilgili meselelerde kendine dayanak noktası olarak "sayg1, işbirliği ve sürdürülebilirlik" kriterlerini esas aldığı ifade edilmektedir. Çin bölge ülkeleriyle ikili ilişkilerinde de aynı prensipler çerçevesinde hareket ettiği anlaşılmaktadır.

Çin'in kolonyal dönemde edinmiş olduğu olumsuz tecrübeler onun devlet egemenliğine olan bağlllığını güçlendirmektedir. Çin'de Batı tarafindan empoze edilen ve adil olmadığı düşünülen hukuki yapılanmalara karş1 bir ön yarg1 bulunmaktadır (Kahler, 2001: 177). 21.yüzyıldaki Çin ise; gelişmiş yapısıyla, gönenç düzeyini giderek arttırmayı hedefleyen konumuyla dünya liderliğine aday seviyededir. Çin uluslararası arenada daha fazla yer elde edebilme yarışı içinde olduğunu her firsatta göstermektedir. Xi Jinping'in Çin'i "uluslararası düzenin koruyucusu" olarak adlandırması (Sphor, 2018: 26) bir bakıma Çin'in mevcut uluslararası sistemde, ihlal edilen haklara karşı adalet savunucusu olarak kendisini konumlandırdığına işaret etmektedir.

Çin'in Arktik'te artan tüm bu faaliyetleri Arktik ülkelerinin dikkatini çekmekte ve bir kısmı bu faaliyetleri egemenliklerine karşı tehdit olarak değerlendirdikleri kaydedilmektedir. Bunların içinden özellikle Baltık 
ülkelerindeki akademik camiada Sino-fobi söylemlerinin yükseldiği görülmektedir (Barannikova ve Bo, 2015: 17).

\section{2. Çin'in Arktik Bölgeye Hukuki Yaklaşımı}

Çin, Arktik bölgeye olan ilgisinin yeni olmadığını, 1925 yılında Spitsbergen Anlaşmasını onayladığını, 2004 y1lında ise $\mathrm{Nu}$ Alesund bölgesinde Arctic Yellow River adinda multidisipliner olarak faaliyet gösteren bir üs kurduğunu, 2013 y1lında Arktik Konsey gözlemci statüsünü elde ettiğini, günümüze dek sayısız bilimsel deney ve araştırmaya imza attığını dile getirmiştir (http://english.gov.cn, 2019).

Arktik Bölge için oluşturulmuş, özel bir anlaşmanın olmaması Çin'in üzerinde durduğu bir husustur. Fakat mevcut durumda BMDHS, Spitsbergen Anlaşması ve diğer ikili anlaşmalara sayg1 duyduğunu belirtmektedir. Çin Arktikle ilgili yayınladığı strateji belgesinde hukuki kurallarla sınırları belirlenmiş olan açık denizler ve uluslararası deniz yatağı alanlarında Arktik ülkesi olmayan ülkelerin egemenlik haklarına, seyrüsefer özgürlüğüne ve uluslararası hukukun sunduğu diğer özgürlüklere dikkat çekmektedir (http://english.gov.cn, 2019). Çünkü Arktik bölge egemen devletlerin uluslararası hukukun kendilerine tanıdığı sınırlar ve şartlar çerçevesinde hak talep ettikleri alan ile hiçbir devletin egemenlik iddiasında bulunamayacağı alanın birleşiminden oluşmaktadır (Xinzhen, 2019: 48).

Fakat Çin klasik uluslararası hukuk anlayışında yer alan belirli boşluklar dolayısıyla hala üzerinde kesin hükümler bulunmayan alanlarla ilgili yine hukuk sinırları çerçevesinde hak talep etmektedir. Örneğin, Çin Arktik bölgeye ait açık deniz alanlarında yapılan balıkçılığın hukuki bağlayıcılık sağlayacak uluslararası bir anlaşmayla desteklenmesi gerektiğini ifade etmektedir (http://english.gov.cn, 2019).

Çin Arktik Bölge ile ilişkili olarak hem Arktik bölge ülkeleri hem de Arktik bölgede toprağ1 olmayan diğer ülkelerle ikili/çoklu işbirliği görüşmeleri ve anlaşmaları yapmaktadır. Örneğin, İzlanda ile yapılan işbirliği anlaşması Çin'in Arktik bölgede ekonomik yatırımlarının önünü açarak siyasi önemini arttırmıştır (Auerswald, 2019; Guschin, 2015). Diğger taraftan Asya merkezli meselelerde bir araya gelen Çin, Japonya ve G. Kore ilk kez 2016 yılında Arktik meselelerini görüşmek üzere üçlü görüşme tertip etmişlerdir (http://www.xinhuanet.com, 2018).

Wu, (2016: 121) Çin'in mevcut yönetim sistemine alternatif olarak oluşturduğu Asya Altyapı Yatırım Bankası örneğini vererek uluslararası düzende yeni yapılar oluşturabilme kapasitesine dikkat çekmektedir. Benzer durumun Arktik bölgedeki mevcut hukuki-siyasi yapılanmaya alternatif bir Çin modelinin oluşmasında da geçerli olacağı tahmin edilmektedir. 
Zhao, (2018) BMDHS'nin Arktik bölgeye uygulanabildiğini belirtmiştir. Fakat Arktik bölgede bilimsel araştırma yapılması, kaynakların çıkarılması ve kullanılması, güvenliğin tesis edilmesi gibi konularda yasal bağlayicillğı olan kuralların bulunmadığını belirterek BMDHS dâhil diğer Arktik yönetim mekanizmalarında bir yenilenmenin gerekliliğinden bahsetmiştir.

Wodiske (2014: 314) BMDHS'nin açık denizler ile ilgili kısmında yasal boşlukların bulunduğunu belirtmiştir. Çin'in açık denizler için öne sürdüğü hak taleplerini de bu hukuki boşluğa bağlamıştır. Böylece açık denizler hususu üzerinden Çin gibi daha başka ülkelerin de bu yasal boşluktan yararlanıp Arktik'te hak talep edebilecekleri iddiasında bulunmuştur.

Rainwater ise (2013: 73-76) Çin'in Arktik bölgede uluslararası hukuku yanlış yorumlayarak hak iddialarında bulunduğunu ve Arktik politikasını bu yönde geliştirdiğini ileri sürerek bölgede revizyonist bir güç olma çabası içinde bulunduğunu iddia etmektedir.

Arktik bölge faaliyetlerini arttırmasılyla birlikte Çin'in bu bölgeyle ilgili başta seyrüsefer kuralları olmak üzere tüm hukuki meseleleri içeren yeni yasal düzenlemelere ihtiyaç duyduğu belirtilmiştir. Bunun da işbirliği çerçevesinde gerçekleşebileceği üzerinde durulmuştur (Barannikova\&Bo, 2015: 16).

\section{3. Çin'in Küresel Arktik Yönetimi Yaklaşımı}

2008'de gerçekleştirilen Ilulissat Deklarasyonuyla Arktik'te kıyısı bulunan ülkeler bu bölgeyle ilgili bir Arktik Anlaşması'nın oluşmaması yönünde karar alarak bu bölgede her açıdan ayrıcalıklı konumda bulunduklarını teyit etmişlerdir (Molenaars, 2019). Arktik Beşlisi'nin özellikle genişletilmiş kıta sahanlığ ile egemenlik hususu üzerinde işbirliği yaptıkları bilinmektedir ( Brosnan ve diğerleri. 2011: 180, 191). Arktik okyanusuna kıyısı bulunan bu beş ülkenin bir nevi kolektif egemenlik ilanı olarak ortaya koydukları Ilulissat deklarasyonu, Arktik Konseyinin daimi üyesi olan İzlanda, Finlandiya ve İsveç tarafindan da olumlu karşlanmamıştır (Young, 2009: 428-429). Arktik Konseyinin kendi içerisinde dahi ayrrlık oluşturan bu durum bölge üzerinde egemenliğin eşitlik ve adalet prensibinin önüne geçtiğini göstermesi bakımından önemlidir.

Ek olarak Rainwater (2015: 146), Kanada'nın AB'nin Arktik Konseyine gözlemci üye olarak başvurusunu veto etmesinin iki tarafın kendi iç meselelerinden doğan anlaşmazlıktan kaynaklandığına, bu durumun konseye taşınarak üyelik meselesinin siyasallaştırıldığına değinmiştir. Bölgede egemenlik haklarını sınırsız genişletme ve tüm dünya devletlerinin hak taleplerini kendi siyasal tercihlerine bağlama anlayışında olan Arktik Beşlisi'nin Arktik Konseyi'nin saygınlı̆̆1 üzerinde de şüphe doğurduğu ortaya çıkmışır. Ayrıca daimi üye ülkelerin ortak görüşü olmadan konseyin 
yaptığı görevleri özetleyen bir deklerasyonun yayınlanamacağı ifade edilmiştir (Sengupta, 2019).

$\mathrm{Bu}$ durum bir nevi Arktik Beşlisi dışında kalan İzlanda, Finlandiya ve İşveç'in 2008'de Ilulissat'ta yapilan toplantıya karşı siyasal duruşlarını dikkate almak olarak yorumlansa da diğer taraftan Arktik'te gözlemci üye statüsünün etkisiz bırakılacağ 1 anlamına da gelmektedir. Nitekim Arktik'e ilginin gün geçtikçe artmasıyla birlikte oluşan bu yeni durumun çok taraflı yeni düzenlemeleri de beraberinde getireceği ve artık bu bölgenin sadece Arktik devletlerinin ayrıcalıklı alanı olarak kabul edilemeyeceği anlaşılmaktadır (Xie, 2015: 63).

Çin'in bölgedeki bu dışlayıcı durum karşısında sessiz kalmadığı, daha çok ikili anlaşmalar çerçevesinde kendine hukuki bir alan yarattı̆̆ gözlenmektedir. Çin Arktik'te yer alan devletlerle olan hukuki ilişkisini arttırarak dolaylı biçimde Arktik politikalarında söz sahibi olmaktadır. Çin'in Arktik'e bu yöntem üzerinden yakınlaşması kısa vadede siyasal ve ekonomik faydalar elde etmesine geçici çözümler sunsa da, uzun vadede Arktik bölgede var olma ihtiyacı için küresel çapta atılımlara ihtiyaç duyacağ değerlendirilmektedir.

Wu (2016:118) Çin'in son zamanlarda Arktik bölgesindeki yükselişini küresel yönetimdeki artan etkisine bağlamıştır. Zaman içerisinde Çin'in Arktik ile ilgili sorun alanlarına duyarlılığı artmış ve Arktik başlı̆ııı küresel ölçekte tartışmaya açmıştır.

Dodds (2016) ise çalısmasında eski kolonyal döneme ait olduğunu öne sürdüğü coğrafi adlandırmalardan Kanada, Amerika ve Rus Arktiği’nin yerine "Küresel Arktik" söyleminin yerleşmesini aldatıcı bularak bu bağlamda bölgede yaşayan yerli halkların yasal hak taleplerinin görmezden gelinebileceğine dikkat çekmiştir.

Çin değişen iklimle birlikte Arktik'teki durumun da değiş̧iğine dikkat çekerek bölgenin Arktik'te toprağı bulunmayan ülkeler için de hayati öneme haiz olduğunu ve tüm insanllğı ilgilendiren bir konumunun bulunduğunu ifade etmeye devam ettiği gözlenmiştir. (http://english.gov.cn, 2019). Çin'in çevre ve iklim bağlamındaki Arktik yaklaşımı bilimsel kanıtlara dayanmakta, eriyen buzulların tüm dünyadaki sistemi derinden etkileyeceği bu bağlamda Arktik bölgeyi küresel kapsamda ele almanın yerinde olacağ1 değerlendirilmektedir. Çin Arktik'e yönelik siyasal yaklaşımını ise "tüm devletlerin ve uluslararası toplumun menfaatlerinin gözetilmesi" olarak beyan etmektedir (http://english.gov.cn, 2019).

Çin'in Arktik söyleminin hem küresel hem de bölgesel özellikleri bir arada taşıdığı ifade edilerek Arktik söyleminin temelde çelişkili olduğuna vurgu yapılmaktadır (Benett, 2015: 654-658). Çin'in bir taraftan bölgede kıyısı bulunan ülkelerin egemenliklerine sayg1 duyarak bölgeselliğe, diğer 
yandan ise bölgede yer almayan ülkelerin de burada hakları olduğunu dile getirerek küreselliğe vurgu yapmasının çelişkili bir durum doğurduğu ifade edilmektedir. Oysaki Çin bölge üzerindeki söylemini, sınırlı egemenlik ve özgür alanların varlığı üzerine inşa etmektedir.

Çin'in Arktik'e küresel olarak yaklaştığına dair bir örnek olarak “2010 yllında Tuğamiral Yin Zhuo'nun Arktik'in tüm insanlığa ait olduğu ve hiçbir milletin egemenliği altında bulunamayacağı" ile ilgili beyanatı referans gösterilmiştir (Kim \& Blank'ten aktaran Bennett, 2015: 658). Çin'in Arktik bölge üzerindeki faaliyetlerine bakıldığında burayı neden çok katmanlı ve çok taraflı bir alan olarak görmek istediği açıktır. Bu bakımdan bölgeyi küresel çerçevede düşünmenin söylemlerden çok eylemlere dayandığını belirtmek gerekecektir. Örneğin: China Telekom şirketinin Arktik bölgeden geçecek fiber-optik kabloların döşenmesi ile ilgili atılımları bulunmaktadır. Bu şirket faaliyetlerini bölge ülkeleri ile işbirliği çerçevesinde gerçekleştirmeyi amaç edinmektedir (Wire Journal International, 2018: 15). Kitalar arasındaki iletişim ağının geliştirilmesi ve güçlendirilmesi konusu küresel işbirliği gerektiren bir meseledir. Bu meselenin başarılı bir şekilde yürütülmesi çok yönlü çalışmanın yanı sıra ciddi anlamda ekonomik birikim gerektirmektedir. Diğer yandan, Çin'in Arktik ülkelerinde başta enerji olmak üzere maden ve değerli metallerin çıkartılması projelerinde yer aldığı ve bu alanlara yüklü miktarda yatırım yaptığı bilinmektedir (Moore, 2015: 12). Örneğin Arktik'e kıyısı olmamasına rağmen Çin ve G.Kore gibi ülkelerin Arktik'teki çevrenin korunmasıyla ilgili sorumluluk paylaşımında bulunmaları örnek bir davranış olarak kabul edilmekte, bunun yanı sıra her iki ülke de bölgede küresel yönetim anlayışııı benimsediklerinin sinyalini vermektedir (Bai, 2015: 687). Bu örnekler Arktik bölgede Çin'in küresel söylem düzeyinden çok küresel eylem düzeyinde etkin olduğunu göstermektedir.

Tüm bu bilgiler 1şığında Çin'in Arktik bölgesinin yönetimi için amaç edindiği politikalar mevcut karar-verme mekanizmalarında aktif rol elde edebilmek ve ikili anlaşmalar üzerinden politikalar uygulamak şeklinde özetlenebilir (Fengshi, 2016: 122). Çin Arktik Konseyine gözlemci üye olma hakkıyla sınırlı temsil yetkisine sahip bulunsa da Çin'in elde ettiği bu üyelik statüsü bir başar1 olarak kabul görmektedir (Xie, 2015: 60). Çin'in bu konumuyla Arktik'te ikili anlaşmalar yaparak var olan hâkim uluslararası düzeni değiştirdiği ve etki düzeyi yüksek alternatif bir alan oluşturduğu değerlendirilmektedir. Çin'in yapmış olduğu ikili anlaşmalarla bölgede dengeleyici bir unsur olarak yer aldığı ve dolaylı olarak Arktik'teki geleneksel uluslararası hukuk yapılarını ve siyasal yönetim anlayışını yeniden şekillendirdiği görülmektedir.

\section{Sonuç}

Devleti, uluslararası sistemi ve özünde insanı ilgilendiren toplumsal ihtiyaçların değişmesiyle birlikte hukuk da evrilmiştir. Geleneksel uluslararası 
hukuk kurallarının çözüm sunamadığı sorunlar karşısında uluslararası hukuka yönelik eleştirilerin de arttı̆̆1 gözlenmiştir. Bu eleştirilerle beraber hukuk farklı bakış açılarıyla yeniden yorumlanmaya başlanmıştır. Geleneksel hukuk çerçevesinde belirlenen deniz yetki alanlarının da eleştiriye tabi tutulduğu gözlenmiştir. Diğer taraftan egemenlik ve uluslararası hukuk anlayışı arasındaki yorumlamalardan doğan farklılıklar sorunların eleştirel boyutta ele alınmasına sebep olmuştur. Özellikle egemen devletin uluslararası hukuk karşısındaki konumu, siyasetin hukuk içerisindeki etkinliği, hukukun adalet temelli mi siyasal temelli mi olduğu vb. konular eleştirel hafiza sayesinde bilim insanlarını üzerinde yeniden düşünmeye sevk eden sorun alanları olarak ortaya çımıştır.

Örneğin, günümüzde Arktik'te aç1k deniz olarak bilinen alanlar ile Arktik'e kıyısı olan devletler tarafindan üzerinde egemenlik iddia edilen deniz yetki alanlarının (Mendeleyev ve Lomonosov hatları örneğinde olduğu gibi) sorunsal özellikler taşıdığı bilinmektedir. Bu alanların statüleri, küresel fayda esas alınmadan belirlendiği takdirde, bölgeye kıyısı bulunan ülkelerin kendi aralarında ya da kiyss bulunmayanlarla yeni sorun alanları meydana getireceği düşünülmektedir. Mevcut hukuki boşlukların farklı yorumlanmasından kaynaklanan uyuşmazlıkların, egemenleri karşı karşıya getirmesiyle birlikte bölgesel ve küresel ölçekli çatışmalara dönüşme riski de bulunmaktadır. Bu bağlamda çatışma riskini ortadan kaldıracak ya da en aza indirgeyecek yeni düzenlemelere, geleneksel hukuk kurallarında yenilenmeye ihtiyaç duyulmaktadır.

Çin'in Arktik stratejisinin temelde uluslararası hukuk çerçevesinden ele alındığı bilinmektedir. Fakat bunun yanında Çin, BMDHS'nin Arktik bölgesiyle ilgili birçok alanda yetersiz kaldığı durumlar bulunduğuna dikkat çekmektedir. Bu bakımdan özellik arz eden alanlarla ilgili yeni anlaşmalar yapılması gerektiğini savunmaktadır. Bu nedenle Çin, mevcut uluslararası hukukun talepleri karşılayamadığı durumlara yönelik olarak reformlara gereksinim duyulduğunu açıkça ifade etmektedir.

Çin Arktik bölgeyi küresel seviyeden ele alarak burasını sadece kı1 devletlerinin hüküm sürdüğü ve özgürce hareket ettiği bir alan olarak görmemektedir. Çin Arktik bölge ülkelerinin mevcut sınırlar içerisinde egemenliklerini tanırken uluslararası hukukun kendisine sunduğu haklara dayanarak aynı şekilde kendi haklarına da saygı gösterilmesini beklemektedir. Çin, bölgede sınırı bulunmayan diğer devletlerin de burada hakları olduğu ilkesini esas alarak Arktik'te özellikle açı denizler, deniz yatağı ve diğer bölgeler üzerinde küresel bir yönetimin yerleşmesi gerektiğinin altını çizmektedir.

Diğer taraftan, Çin'in bölgede ikili anlaşmalar yoluyla kendine ayrı bir alan açarak yeni bir hukuki zemin yarattı̆̆ dikkat çekmektedir. Çin'in Arktik bölgeye yapmış olduğu yüklü miktardaki yatırımlar bölge ülkelerinin 
ekonomilerinde artı değer oluşturmaktadır. Bu durum Çin'e yönelik ekonomik bağımlılı̆̆ arttırmakta ve Çin'in bölgede varlığını kuvvetlendirmektedir.

Çin'in küresel siyaset ve ekonomide etki alanını arttırmasının Arktik üzerinde de yansımaları olmaktadır. Özellikle Çin'in "Bir Kuşak Bir Yol" projesinin kutup ayağıyla ilgili olan kısmı bunun bir göstergesidir. Çin'in bu proje kapsamında bölgedeki yasal mevzuatın belirlenmesi hususunda çalışmalarının bulunduğu da bilinmektedir. İklimsel değişimle birlikte bölgede artan faaliyetlerin hukuki bir zemine bağlanması için Çin tarafindan özel bir çabanın sarf edildiği gözlenmektedir. Çin bölgedeki tüm hak talepleri ve işbirliği alanlarının herkesçe kabul görecek bir hukuki zemin içerisinde yasalaştırılmasını ve bunun hayata geçirilmesini hedeflemektedir.

Sonuç olarak, Çin Arktik'in küresel bir değer olduğunu savunmaktadır. Çin eleştirel hukuk bağlamında geleneksel uluslararası hukuk düzeninin Arktik bölgesinde bu haliyle ihtiyaçlara cevap veremediğini düşünmektedir. $\mathrm{Bu}$ yüzden hukukta yer alan boşlukların gerekli anlaşmalarla doldurularak giderilmesini ve adaletin sağlanmasını talep etmektedir. Bu bağlamda Arktik Konseyi gibi geleneksel bir yapıyla yönetimin sürdürülemeyeceğinin, Arktik bölgesi için küresel boyutta bir düzenlemenin gerekliliğinin sinyallerini vermektedir. 


\section{Kaynakça}

Abbott K. W. and Snidal D. (2001)Hard and Soft Law in International Governance. Ed. Goldstein J. Kahler M. Keohane R. O. Slaughter A. M. Legalization and World Politics. Cambridge. MIT Press. ss. (3772)

Agamben G. (1998). Homo Sacer: Sovereign Power and Bare Life. Translated by Daniel Heller Roazen. Stanford. Stanford University Press.

Agreements.( Jul 07, 2015)(https://arctic-council.org/index.php/en/ourwork/agreements) (08.06.2019).

Akman S..T. (2012). Hukuk politika ilişkisi bakımından eleștirel Hukuk Çalışmaları hareketi. Ankara Üniversitesi Hukuk Fakültesi Dergisi. 61(4). ss. (1271-1306)

Anghie A. (2014)Towards a Postcolonial International Law. Ed. Singh P. \&Mayer B. Critical International Law: Postrealism, Postcolonialism, and Transnationalism. Oxford. Oxford University Press. ss. (123-142)

Annual Report to Congress: Military and Security Developments Involving the People's Republic of China 2019, Office of the Secretary of Defence, 2019. https://media.defense.gov/2019/May/02/2002127082/-1/1/1/2019_CHINA_MILITARY_POWER_REPORT.pdf, (20.05.2019)

Auerswald D. (2019) China's Multifaceted Arctic Strategy. https://warontherocks.com/2019/05/chinas-multifaceted-arcticstrategy/, (26.05.2019)

Bai J.(2015). The IMO Polar Code: The Emerging Rules of Arctic Shipping Governance. The International Journal of Marine And Coastal Law. (30). ss. (674-699).

Barannikova A.O, Bo D. (2015) The Development of Chinese-Russian Relations and Strengthening China's Position in the Arctic. AsiaPacific Journal of Marine Science \& Education. 5 (2). ss. (10-20)

Bennett M.M. (2015). How China Sees the Arctic: Reading Between Extraregional and Intraregional Narratives. Geopolitics, 20. ss. (645668)

Bilimsel Dergilerde Makaleler

Brosnan I.G, Leschine T. M, Miles E. L.(2011). Cooperation or Conflict in a Changing Arctic? Ocean Development \& International Law. 42. ss. (173-210) 
China Interested in Fiber Optic Cable System that Crosses Arctic Circle (2018).Wire Journal International (January).s. (15)

China Today. (March 1, 2018)

China, Japan, ROK Agree to Strengthen Research Cooperation on Arctic. Xinhua.2018.06.09.http://www.xinhuanet.com/english/201806/09/c_137240638.htm, (26.05.2019)

China's Arctic Policy. The State Council Information Office of the People's Republic of China. January 2018. http://english.gov.cn/archive/white_paper/2018/01/26/content _281476026660336.htm, (29.05.2019)

China's Arctic Policy: How China Aligns Rights and Interests. http://www.europarl.europa.eu/RegData/etudes/BRIE/2018/62 0231/EPRS_BRI(2018)620231_EN.pdf, (28.05.2019)

Dodds K. (Feb 18, 2016). What We Mean When We Talk About the Global Arctic.

"Finland: Lavrov says Russia is 'open for broadest cooperation in the Arctic"' May 07, 2019, https://ruptly.tv/en/videos/20190507-010 , (18.05.2019)

Foucault M. (2011). Entelektüelin Siyasi İslevi. Çev. Ergüden I., Akınhay O., Keskin F. 3. Baskı. İstanbul. Ayrıntı Yayınları. ss. (294-299)

Gardiner R. K. (2003). International Law. Harlow. Pearson Longman.

Guschin A. (2015) China, Iceland and the Arctic. https:/ thediplomat.com/2015/05/china-iceland-and-the-arctic/, (26.05.2019)

Hickey J. (2014). Law-making and the Law of the Sea: The BP Deepwater Horizon oil spill in the Gulf of Mexico. Ed. Liivoja R. and Petman J. International Law-making: Essays in Honour of Jan Klabbers. Oxon. Routledge. ss. (271-282)

https://www.newsdeeply.com/arctic/community/2016/02/18/what-wemean-when-we-talk-about-the-global-arctic, (02.06.2019).

https://www.un.org/depts/los/convention_agreements/texts/unclos/uncl os_e.pdf, (11.06.2019)

Humrich C.(2013). Fragmented International Governance of Arctic Offshore Oil: Governance Challenges and Institutional Improvement. Global Environmental Politics. 13 (3), ss. (79-99)

International Law, Economic Ideology and Seabed Resources. Nordic Journal of International Law. (65). ss. (533-555). 
Kahler. M.(2001). Legalization as Strategy: The Asia-Pasific Case. Ed. Goldstein J.L., Kahler M., Keohane R.O., Slaughter A.M. Legalization and World Politics. Cambridge. MIT Press.

Kennedy D. (1996) International Law and Nineteenth Century: History of An Illusion. Nordic Journal of International Law. (65). ss. (385-420)

Kınacıŏlu M. (2012). War on Terror' and Hegemony: International LawMaking Regarding Terrorism After 9/11. Uluslararası İlişkiler, 8(32) ss. (67-83)

Koskenniemi M. \& Lehto M. (1996). The Privilege of Universality:

Koskenniemi M. (1997) Hierarchy in International Law: A Sketch. European Journal of International Law. (8). ss. (566-582)

Koskenniemi M. (2004a) The Gentle Civilizer of Nations: The Rise and Fall of International Law 1870-1960. Cambridge. Cambridge University Press.

Koskenniemi M. (2004b). International Law and Hegemony: A Reconfiguration. Cambridge Review of International Affairs,17(2). ss. (197-218)

Koskenniemi M. (2005) From Apology to Utopia: The Structure of International Legal Argument Reissue with a New Epilogue. Cambridge. Cambridge University Press.

Koskenniemi M. (2016). What is Critical Research in International Law? Celebrating Structuralism. Leiden Journal of International Law. (29) ss. (727-735).

Krasner S. D. (1999) Sovereignty: Organized Hypocrisy. Princeton. Princeton University Press.

Krisch N. (2005). International Law in Times of Hegemony: Unequal Power and the Shaping of the International Legal Order. The European Journal of International Law. 16(3). ss. (369-408)

Lauterpacht H. (2011). The Function of Law in the International Community. Oxford. Oxford University Press.

Lim K.S. (2018). China's Arctic Policy \& the Polar Silk Road Vision. Arctic Yearbook 2018. https:/ /arcticyearbook.com/images/yearbook/2018/Scholarly_Pa pers/24_AY2018_Kong.pdf, (07.06.2019).

Mastanduno M. (2001). A Realist View: Three Images of the Coming International Order. Ed. Paul T.V.\& Hall J. A. International Order and the Future of World Politics. Cambridge. Cambridge University Press. ss. (19-40) 
Meray S. L. (1977) Uluslararası Hukuk ve Örgütler El Kitabı. Ankara. Ankara Üniversitesi Basimevi.

Molenaars D. (Jun 05, 2019). Chinese Activity in the Arctic. https://qrius.com/chinese-activity-in-the-arctic/, (06.06.2019)

Moore M.A. (2015) Panda in the Arctic. Canadian Sailing (Mar.2)

Müllerson R. (2003). International Law Between Anarchy and Hegemony. ss. (221-250) Ed. Petman J.\& Klabbers J. Nordic Cosmopolitanism: Essay in International law for Martti Koskenniemi. Leiden. Brill Academic Publisers.

Nanda D. (2019). India's Arctic Potential. Occasional Papers 186. https:/ / www.orfonline.org/research/indias-arctic-potential48263/, (11.06.2019)

Pahuja S. (2012).Conserving the World's Resources? Ed. Crawford J. and Koskenniemi M. The Cambridge Companion to International Law. Cambridge. Cambridge University Press. ss. (398-420)

Pazarc1 H. (2010) Uluslararası Hukuk. 9. Baskı. Ankara. Turhan Kitabevi.

Rainwater S. (2013). Race to the North: China's Arctic Strategy and Its Implications. Naval War College Review. 66. (2). ss. (62-82)

Rainwater S. (2015). International Law and the "Globalization" of the Arctic: Assessing the Rights of Non-Arctic States in the High North. Emory International Law Review. Vol.30(1). ss. (115-153)

Savin L. (2018). China and Multipolarity. https:/ /www.geopolitica.ru/en/article/china-and-multipolarity, (08.06.2019)

Schmitt C. (2012) Siyasal Kavramı. 2. Baskı. Çev. Ece Göztepe. İstanbul. Metis Yayınlar1.

Schrijver N. (2016). Managing the global commons: common good or common sink? Third World Quarterly. 37(7). ss. (1252-1267)

Sengupta S. (May 6, 2019). "United States Rattles Arctic Talks With a Sharp Warning to China and Russia”, https://www.nytimes.com/2019/05/06/climate/pompeo-arcticchina-russia.html (21.05.2019)

Sevuntus L. (2018). Chinese Arctic Road and Belt. Chinese American Forum. Volume XXXIII No.3, Jan-March. ss. (13-17)

Sophokles. (2018) Antigone. Çev. Ari Çokona. İstanbul. Türkiye İş Bankası Kültür Yayınları. 
Sur M. (2010). Uluslararası Hukukun Esaslar. Güncellenmiş 4. Bask1. İstanbul. Beta Yayınları.

Takei Y. (2015). The Role of the Arctic Council from an International Law Perspective: Past, Present and Future. The Yearbook Of Polar Law, 6, (349-374)

Trubek D.M. (2013) Law, State and the New Developmentalism: An Introduction. Ed. Trubek D. M., Garcia H. A., Coutinho D. R., Santos A. Law and New Developmental State: The Brazilian Experiance in Latin American Context. Cambridge. Cambridge University Press. ss. (3-27)

Tucker P. (May 3, 2019). Pentagon Warns Of China's Rise in the Arctic, Missile Subs, Influence Operations. https://www.govexec.com/defense/2019/05/pentagon-warnschinas-rise-arctic-missile-subs-influence-operations/156734/, (28. 05. 2019)

Why China Wants to Expand Its Arctic Footprint. Dec 24, 2018. https://worldview.stratfor.com/article/why-china-wants-expandits-arctic-footprint, (28.05.2019)

Wodiske B. (2014). Preventing the Melting of the Arctic Council: China as a Permanent Observer and What It Means for the Council and the Environment. Loy. L.A. Int'l \& Comp. L. Rev. Vol.36. ss. (305-330)

Wu F. (2016) China's Ascent in Global Governance and the Arctic. Bестник СПбГУ. Сер. 6. Вып. 2. ss. (118-126).

Xie K. (2015). Some BRICS in the Arctic: Developing Powers Look North. Harvard International Review. (spring). ss. (60-63)

Xinzhen L. ( May 30, 2019). Defending China's Rights in the Arctic. Beijing Review.

Young O. (2012). Arctic Politics in an Era of Global Change. The Brown Journal of World Affairs.(Fall/Winter).vol. xix, (1).ss. (165-178)

Young O.R. (2009). The Arctic in Play: Governance in a Time of Rapid Change. The International Journal of Marine and Coastal Law. (24) ss. (423-442)

Zhao L. (2016). Arctic Governance Paradigm and the Role of China. Вестник СПбГУ. Сер. 6. Вып. 2 ss. (127-138).

Zhao L. (2018). Arctic Governance Challenges and Opportunities. https://www.cfr.org/report/arctic-governance, (31.05.2019) 